\title{
Crítica, cinema e história: planos de um diálogo na crítica de Jean-Claude Bernardet nos anos 60
}

\author{
Maria Ignês Carlos Magno
}

\section{Resumo:}

O texto é parte de um estudo sobre a crítica como ramo da produção teórica e cultural no Brasil. Mais precisamente, os momentos em que aparece como espaço de reflexão e indagação de um contexto e época. O foco de estudo é a produção crítica de Jean-Claude Bernardet e os diálogos que estabeleceu com a história e com a cinematografia brasileira nos anos de 1960.

\section{Palavras Chave:}

crítica, cinema, história.

\begin{abstract}
:
The text is part of a study about the criticism as a branch of Brazilian's theoretical and cultural production. Precisely, the moments which it appears as a place of reflection and investigation of a context and time. The focus of study is the critical production by Jean-Claude Bernardet and the dialogues that established with history and the Brazilian cinematography in the 1960's.
\end{abstract}

\section{Keywords:}

criticism, cinema, history.

Dentre as muitas possibilidades que a produção crítica nos abre para estudo, análises e interpretações, uma delas é a do crítico enquanto leitor e produtor de conhecimento histórico elaborado através de um tipo diferenciado de documento, quais sejam as linguagens artísticas. No caso de Jean-Claude Bernardet, o cinema, e de uma narrativa específica da história, o filme.

Tomando o conjunto da produção do crítico no período de 1960/67, o que apreendemos, além de uma série de temas que povoavam o universo histórico do momento, é uma discussão e um aprofundamento do estudo sobre as representações das classes no cinema brasileiro e, em especial, as relações entre classe média, incluindo aí os cineastas, e o momento histórico em questão.

Embora a classe média tenha sido a classe social escolhida para seus estudos e tese, é possível percebermos que desde sua estréia como crítico o que está no centro de suas reflexões são as lutas sociais. Lutas sociais que se dão em vários níveis: no interior das classes, nas relações entre classes, nas relações entre classes e sistemas, no interior do próprio sistema e nas produções culturais. Lutas estas que podem ou não aparecer de maneira clara e explícitas nas produções culturais. Como cabia ao crítico desvendá-las, Jean-Claude Bernardet procurou, desde o início, mostrar como apareciam e foram tratadas estética e politicamente por seus autores, bem como a sua visão como crítico.

O fato de as lutas sociais se darem em épocas históricas e classes sociais de uma determinada maneira, notamos que em suas primeiras críticas, as classes analisadas foram a burguesia e o campesinato. A burguesia foi discutida frente ao capital internacional e nacional, quanto ao seu projeto, enquanto classe condutora de um processo e em relação ao povo. Já o campesinato foi buscado nos filmes sobre o cangaço, nas comédias de 
Mazzaroppi, culminando com o estudo de «Deus e o diabo na terra do sol». Também recorreu a filmes estrangeiros, não apenas como justificativa de reflexões, mas como forma do espectador ser chamado a pensar nos problemas e na realidade nacional. O povo, implícito em todas as análises, só foi abordado diretamente em «Barravento» e em «O pagador de promessas». A classe média foi, inicialmente, tratada como classe em «Bonitinha, mas ordinária». A maioria dos filmes analisados naquele período foi retomada posteriormente sob outros enfoques, ou redimensionados dentro da mesma temática.

\section{A crítica e a leitura da história representada no cinema}

Durante os anos de 1955/64, um dos temas centrais dos debates entre os teóricos da época era o da Revolução Brasileira como forma de libertação das amarras que os sistemas: colonial e neocolonial levaram a maioria das nações colonizadas ou periféricas a um atraso econômico e político no contexto do capitalismo mundial. As transformações provocadas no interior do capitalismo após o término da guerra, o desenvolvimento das forças produtivas, o progresso econômico e social dos povos de uma maneira geral fizeram com que se acreditasse que era possível a todos participar de tal progresso como nações autônomas e auto-sustentáveis. O Brasil não ficou imune àquele otimismo. Prova e exemplo da euforia foi a criação dos centros de estudos que tinham como finalidade investigar a realidade brasileira e elaborar projetos de desenvolvimento que viabilizassem tais desejos. Exemplo disso foi, entre outros fatos, o Instituto Superior de Estudos Brasileiros (ISEB), órgão ligado ao Ministério de Educação, cuja responsabilidade era a de elaborar uma ideologia desenvolvimentista para o Brasil.

Sob esse cenário Jean-Claude Bernardet estabeleceu alguns diálogos com a história e com o temário representado no cinema. A situação da burguesia nacional no contexto das transformações do capitalismo e o projeto para o Brasil foram discutidas no filme «O pagador de promessas». Diante da industrialização e as mudanças provocadas pelo desenvolvimento do capitalismo nas estruturas sociais e nas relações de classe, abordou os documentários «Arraial do Cabo», «Aruanda» e «Apelo». A estagnação econômica e social apareceu na crítica ao filme «Porto das Caixas». A sobreposição e a contaminação dos valores burgueses sobre a classe média foi delineada em «Bonitinha, mas ordinária».

Em «O pagador de promessas» Bernardet debateu diretamente com a burguesia nacional e sua ambígua posição histórica. Sob o título «O pagador de compromissos», inicia suas análises em torno do filme de Anselmo Duarte e diálogos com a burguesia nacional.

Após situar «O pagador de promessas» no contexto do movimento cinematográfico brasileiro internacional e perante a crítica, expõe o que considerou significativo, ou seja, o fato de o filme de Anselmo Duarte não ter se prendido a uma temática estrangeira e o de ser muito favorável à nossa indústria cinematográfica, porque possibilitou tanto o reconhecimento internacional como dava ao povo a confiança no cinema brasileiro.

Afirmava ainda que o mais positivo em «O pagador de promessas» foi tornar possível a integração da cinematografia no fortalecimento da burguesia ligada aos interesses nacionais, no seu desenvolvimento financeiro e cultural. Que apesar da fragilidade era uma conquista para a grande camada da burguesia que estava lutando para defender seus interesses.

Tais afirmações situariam o crítico no quadro de uma das correntes políticas do desenvolvimentismo, o da burguesia nacional e de sua luta contra o capital imperialista. Interessada no desenvolvimento do país e das classes, a burguesia nacional estaria próxima das lutas e do desenvolvimento do povo brasileiro. No entanto, 
toda sua análise recaiu sobre a ambigüidade, ou melhor, sobre as muitas ambigüidades da classe burguesa e do filme. De acordo com o crítico, no que se referia essencialmente à burguesia, dizia que a ambigüidade da burguesia nacional era própria de uma situação, de um momento de luta para se desenvolver econômica e culturalmente. Pois esta vivia a contradição de uma aparente atitude progressista, que no fundo não podia se radicalizar e promover um também desenvolvimento das massas, e nessa contradição e ambigüidade, firmava seu caráter de classe e, aos olhos dos poderes públicos, o filme e a burguesia nacional, ao favorecer um contato com a massa, servia como divulgadora de uma linha política. Contradição de uma classe que, para se realizar, precisava se aproximar da massa em discurso e na prática, construindo um projeto desenvolvimentista que promovesse mudanças sociais e, ao mesmo tempo, assegurasse a sua manutenção no poder. É nesse sentido que o crítico discutiu a ambigüidade, porque, embora o projeto fosse antiimperialista e propusesse o desenvolvimento da sociedade como um todo, ele não anulava seu caráter de classe e nem os seus conflitos.

A ambigüidade do filme foi discutida na oposição assumida ante a Igreja e o povo. De acordo com suas análises, aparentemente o filme se posicionava contra a Igreja. Apesar de ter sido entendido, na maioria das vezes dessa maneira, na verdade, não se colocava contra a Igreja, e pode até ser considerado como uma lição de humildade cristã.

A partir dessas colocações, Bernardet apresenta como se dá a ambigüidade no filme:

O padre Olavo não é mau; se proíbe o ingresso do Zé do Burro no templo, se é intransigente, é após meditação e rezas, é cumprindo o que ela acha ser o seu dever de sacerdote; o padre Olavo, sendo homem, pode se enganar e ser orgulhoso.(p:60).Outrossim, o filme retrata uma situação verdadeira que, até, poderia ser exemplar; e, então, a frase do monsenhor sobre o papel que a igreja deve de vez em quando desempenhar, deixa de ser satírica (BERNARDET, 1962: 60-1).

Pela voz do monsenhor anuncia o papel político da Igreja: num momento de distúrbios e de transformações, a Igreja deve se adaptar, se modificar: se permanecer rígida, corre o risco de se distanciar dos fiéis e do povo: enquanto que, se se moldar à situação, pode acumular seu poder.

Poder, instituição e classe que foram retomados pelo crítico e analisados em 1965, como um filme apólogo, bastando substituir a Igreja pelo governo em termos de retrato da linha política a que certos setores da esquerda vinham adotando na época de sua primeira análise (1961), na qual dizia que o governo e os dirigentes eram aceitos, e a esquerda solicita-lhes que integrem um pouco mais o povo na vida do País.

Quanto ao povo, a ambigüidade é mostrada através da personagem Zé do Burro.

Zé resiste a todos os obstáculos que a sociedade burguesa coloca diante de quem quer se manter digno até o fim, de quem não abdica das suas idéias: a forte estrutura de organismos de opressão (a administração da igreja e da polícia), a perversão das grandes cidades, as corrupções das grandes cidades, etc. Encontra-se numa situação que, se prolongada, poderia modificá-lo. Isto se verifica quando Zé do Burro diz que não é revoltado, mas que poderia ficar. A sua morte corta essa possibilidade de evolução. Quanto ao povo, passa de papel de coro a uma participação insuficientemente motivada. Disso resulta uma grande confusão. As massas têm direito de participar ativamente de todas as instituições da sociedade.(...) a luta deve ser travada não só para que participem, mas também para que se libertem do entrave da superstição, e seguem, assim, a conscientizar a sua situação. Sem esse último fator, um líder não tem sentido, porque tanto pode ser empregado em favor das massas como da burguesia. Esse é, atualmente, um dos motivos da ambigüidade das manifestações burguesas (BERNARDET, 1962: 61). 
Para Bernardet, o filme teria sido muito mais incisivo se, ao invés de encerrar-se como pretensa vitória, mostrasse o quão ilusória é essa vitória e tentasse colocar em questão a linha política que ela supõe.

Esteticamente, Bernardet, embora não tenha concordado com o academismo do filme, apresenta-o e discute-o em seus aspectos cinematográficos. Para o crítico, Anselmo Duarte havia sido bastante feliz nas soluções encontradas quanto ao cenário sóbrio da Bahia e o folclore, não insistindo em soluções complicadas. Fora feliz também na adaptação da peça de Dias Gomes, conservando a unidade de ação, tempo e lugar, dizimando o espaço. Analisa a fotografia, considerada de grande presença nos primeiros planos. Dizia que o filme, pela segurança das formas, compensava as incertezas do fundo. Era, para o crítico, um filme artesanal e bem feito. Ao analisar as personagens em sua pouca adequação ao tipo nordestino, elogiou a composição laboriosa dada ao protagonista por Leonardo Villar. No entanto e também, o personagem interpretado pelo ator, foi analisado sob o enfoque da ambigüidade. Para Bernardet, se de um lado, Zé do Burro resistiu a todos os obstáculos que a sociedade burguesa colocou diante de quem queria manter a dignidade, de quem não abdicava de suas idéias; de outro, podia servir tanto à burguesia quanto à massa.

Em «Arraial do Cabo», «Aruanda» e «Apelo», discutiu os efeitos da industrialização sobre os espaços sociais e naturais. Em «Arraial do Cabo», a fábrica é a causadora do desequilíbrio na aldeia e na vida dos pescadores. «Aruanda» mostra a vida de pessoas que viviam à margem de qualquer progresso técnico que a industrialização vinha favorecendo desde a Revolução Industrial. Em «Apelo» aponta os mecanismos do processo que geraram a devastação da natureza que, em troca do progresso desordenado e inconseqüente, queima a vegetação, empobrecendo o solo e os habitantes dos locais destruídos.

Nestes documentários, a referência à burguesia e sua política de industrialização deram-se de modo indireto, mas não menos exposto, se atentarmos para o fato de que, mesmo que o foco principal de análise tenham sido as diferentes montagens utilizadas pelos diretores para representar aspectos da realidade, a sua preocupação central era a de que, através da montagem, se mostrassem não apenas os efeitos do desenvolvimento do capitalismo sobre as regiões e agrupamentos humanos, mas também os mecanismos do sistema, e possibilitasse a percepção de uma política orientada unicamente para atender aos interesses de uma classe e do capital. Sua posição não era a de negar o desenvolvimento e nem a industrialização, uma vez que estes já estavam evidentes desde muito. O que questionava na representação cinematográfica era a simples constatação dos problemas, e propunha que se apresentassem de maneira clara os mecanismos e as engrenagens do sistema e política, para que o público pudesse chegar à consciência da realidade e sobre ela se posicionasse.

Exemplos disso podem ser apreendidos no interior de cada um dos textos. Ao criticar a montagem de «Arraial do Cabo», de Paulo César Saraceni e Mário Carneiro, explicava:

Eles mostravam a fábrica, mostravam a pesca, a que dera maior ênfase, já que o filme devia tratar dos pescadores. Vemos o mar, vemos os rostos marcados, as redes e a fábrica: carros gigantescos, lentos, esmagadores trazem pessoal à fábrica; os operários marcando o ponto se assemelham a prisioneiros. Logo, a fábrica é o mal, a pesca é o bem que se perde, que se macula. $\mathrm{O}$ homem está sendo prejudicado, o que considerava um "clichê" e dos mais convencionais. O homem junto à natureza, trabalhando os elementos naturais com as mãos, conhece uma espécie de paz, é feliz (...) o homem da fábrica é infeliz. Então defendemos a felicidade do primeiro. Essa luta contra a industrialização, que consiste em ignorá-la, é a atitude de avestruz que esconde sua cabeça na areia. Além de se tratar de uma atitude reacionária, por ser nostálgica, não sabemos em que situação a fábrica colocou os pescadores (BERNARDET, 1961: 52). 
Em «Aruanda», discute a marginalização de regiões e comunidades diante do desenvolvimento, do progresso técnico ou social, esquecidos e à parte do mundo. Após nos situar na história narrada no documentário de Linduarte Noronha, filmado em Serra do Talhado, na Paraíba, e que conta a história de escravos brasileiros que, em meados do século passado, fugiram, pararam perto do primeiro lago que encontraram.

Mais gente veio depois, formou-se uma aldeia que vive hoje da cerâmica, trabalho feito por mulheres. As jarras são vendidas na feira mais próxima. É um povoado sem desenvolvimento nenhum, que vive à margem do mundo, ignorando qualquer progresso técnico ou social (...) Vemos cruamente homens viverem de elementos primários, sem alegria especial, nem tristeza: vêmo-los andar, trabalhar, não chegando a existir como indivíduos (BERNARDET, 1961: 54).

Sobre o documentário «Apelo», o crítico afirma que, juntamente com «Aruanda», Apelo foi o documentário que melhor representou a problemática do desenvolvimento capitalista. Apesar de o documentário ter sido feito a partir de uma tese envolvendo muitas pesquisas científicas, e estas afirmavam que a pobreza do solo advinha dos métodos primitivos empregados e não da falta de água, o que Trigueirinho Neto mostrou não foi a sua ilustração, mas os mecanismos utilizados. A tese defendia um reflorestamento cientificamente orientado, o autor mostrou o que havia de urgente e não apenas os métodos antiquados dos indígenas e suas queimadas, mas também os tratores que derrubavam as árvores. Que o autor era um homem ligado ao Brasil não havia dúvidas, afirmava o crítico e "a prova estava na violência e também amargor do seu filme. Mas, essa ligação não o levou a mostrar os sofrimentos da terra brasileira. Do Brasil não se vê nada"

(BERNARDET, 1978: 58). Segundo Bernardet, Trigueirinho desnudou "os mecanismos destes sofrimentos, armado com tais abstrações, tendo a possibilidade de encontrar os mecanismos" (BERNARDET, 1978: 58). Segundo o crítico, nesse contexto de devastação e ausências, o homem nordestino aparece entregue à mesma sorte da vegetação. O documentário fala do Brasil, mas do Brasil nada nos mostra, o que «Apelo» faz é mostrar os mecanismos dos sofrimentos. Ao falar do Brasil sem mostrá-lo, fala de todos os lugares do mundo imersos nas engrenagens do capitalismo.

O surgimento, nos primeiros anos da década de 1960, de várias frentes de debates sobre temas como: subdesenvolvimento, desenvolvimento acelerado, processos de tomada de consciência, planejamento e liberdade, estagnação econômica e dependência se avolumaram em todos os níveis e produções teóricoculturais. A superação de um Brasil arcaico e a resolução das disparidades regionais, tanto no campo econômico como no cultural, era colocado e entendido como parte de um dilema para os intelectuais que deviam estar atentos às mudanças e à situação dos chamados países periféricos.

O cinema novo não se furtou a nenhum desses debates e o tema da estagnação econômica das regiões, das cidades e das pessoas provocadas pelo desenvolvimento desigual do sistema foi apresentado por Paulo César Saraceni em seu polêmico filme «Porto das Caixas». Do silêncio estratégico ocorrido desde o lançamento e distribuição, aos embates entre críticos, políticos, argumentista e teórico em geral, «Porto das Caixas» retrata a situação de uma cidade de interior que ficou à margem de tudo, esquecida pelo progresso e pela civilização.

Como parte dessa polêmica, «Porto das Caixas» foi tomado por Bernardet, como uma continuação temática iniciada em «Arraial do Cabo»,

onde a vida é morta, não se sabe onde, não se sabe porquê, onde a estagnação da cidade, das personagens e da vida procurou apresentar a situação do Brasil. «Porto das Caixas» apresenta a que ponto de decomposição chegou uma comunidade. Não se trabalha em «Porto das Caixas». Passam trens, mas não param. Se há uma fábrica, deixou de funcionar há muito tempo; sobram ruínas. Se há um convento, já foi invadido pela vegetação. Falta pouco para que a natureza, a vegetação e a pedra se 
tornem soberanas, e que o homem não passe de uma longuínqua lembrança (BERNARDET, 1964: $82)$.

Essa estagnação, completa Bernardet, está presente na ação e nos personagens. Tal atmosfera retrata a vida de uma cidade do interior do Brasil que ficou à margem de tudo, esquecida pelo progresso e pela civilização, e que nem força encontra para reivindicar uma vida mais digna. Essa ausência de força a que se refere foi exemplificada pelo crítico na cena do comício:

O comício, provocado por candidatos à cata de votos, não representa, como se tem pensado, um menosprezo pelas lutas sociais. Não há mais vitalidade para as lutas sociais que para o amor. $\mathrm{O}$ comício tenta mostrar a que nível de decomposição pode chegar a vida em uma comunidade (BERNARDET, 1964: 84).

Discussão criada, entre outras de ordem estética, pelo fato de Saraceni ter apresentado, além da estagnação econômica, a decomposição e o esmorecimento das lutas sociais exatamente num momento em que se delineava uma revolução social e uma redefinição de estratégias das esquerdas: 1963/64 - data de lançamento do filme.

Os textos apresentados não foram os únicos analisados pelo crítico, bem como os filmes não foram os únicos que trataram de temas ligados à história da época em questão. O que acompanhamos foi apenas uma pequena parte dos diálogos que o crítico travou diretamente com a história e com a cinematografia brasileira. Diálogos que Jean-Claude Bernardet estabeleceu com histórias narradas pelo cinema e que nos possibilita compreender o duplo exercício que o cinema e a crítica nos proporcionam: o conhecimento de alguns dos temários de uma época representados pelo cinema e as análises estéticas de um filme.

\section{Bibliografia:}

BERNARDET, Jean-Claude. «Dois Documentários». "Suplemento Literário" de O Estado de São Paulo, 12/8/61. In: «Trajetória Crítica». São Paulo: Livraria Editora Polis LTDA, 1978.

BERNARDET, Jean-Claude. «Dois Documentários». "Suplemento Literário" de O Estado de São Paulo, 12/8/61. In «Trajetória Crítica». São Paulo: Livraria Editora Polis LTDA, 1978.

BERNARDET, Jean-Claude. «O Pagador de Compromissos». "Suplemento Literário" de O Estado de São Paulo, 8/9/62. In «Trajetória Crítica». São Paulo: Livraria Editora Polis LTDA, 1978.

BERNARDET, Jean-Claude. «O Pagador de Compromissos». "Suplemento Literário" de O Estado de São Paulo, 8/9/62. In «Trajetória Crítica». São Paulo: Livraria Editora Polis LTDA, 1978.

BERNARDET, Jean-Claude. «O Pagador de Compromissos». "Suplemento Literário" de O Estado de São Paulo, 8/9/62. In «Trajetória Crítica». São Paulo: Livraria Editora Polis LTDA, 1978.

BERNARDET, Jean-Claude. «Porto das Caixas I». Última Hora, 21/2/64. In: «Trajetória Crítica». São Paulo: 
Livraria Editora Polis LTDA, 1978.

BERNARDET, Jean-Claude. «Porto das Caixas II». Última Hora, 22/2/64. In: «Trajetória Crítica». São Paulo: Livraria Editora Polis LTDA, 1978.

BERNARDET, Jean-Claude. «Trajetória Crítica». São Paulo: Polis, 1978.

BERNARDET, Jean-Claude. «O Pagador de Compromissos». In: «Trajetória Crítica». São Paulo: Polis, 1978, pp. 59-63.

BERNARDET, Jean-Claude. «Dois documentários». In: «Trajetória Crítica». São Paulo: Polis, 1978, pp. 5155.

BERNARDET, Jean-Claude. «Apelo, um documentário». In: «Trajetória Crítica». São Paulo: Polis, 1978, pp. 56-59.

BERNARDET, Jean-Claude. «Porto das Caixas I e II». In: «Trajetória Crítica». São Paulo: Polis: 1978, pp. 82-84.

\section{Mini Currículo :}

Doutora e professora do Mestrado em Comunicação da Universidade Anhembi Morumbi (São Paulo). E-mail: unsigster@gmail.com. 